\title{
5 Synthesis: Evolving Fields of Interest
}

This chapter is a synthesis of the previous chapters. It elaborates the connections between the three thematic dimensions of (1) creative industries, of (2) place attachment and belonging (roots), and of (3) mobility studies and multiple place attachment (routes). The aim of this chapter is to derive the central research questions. During one of my former research projects in the 6th EU Framework Programme, the ACRE project ${ }^{56}$, I observed that there are transnational migrants who work in creative industries and who frequently circulate between places in different countries where they make use of local social networks. Therefore, I drew on the literature on creative industries to understand the specificity of the economic sector (chapter 2). Then, I discussed concepts such as home/Heimat, place-based identity, dwelling and sedentariness in order to understand how people are rooted in space and in places (chapter 3). And finally, I studied literature on mobile lifestyles such as transnational migration and multilocality (chapter 4). Now I will use the insights from these chapters in order to sketch out three 'theoretical figures', or Weberian ideal types (cf. Werner, 2009) let's call them Merlin, Hannah and Daniel. I will use these characters to illustrate some paradoxical constellations between the different discussions on creative industries, 'roots', and 'routes'. Based on these paradoxes, I will sketch out the relevant research questions, which form different evolving fields of interest for this book.

\section{Meet Merlin}

Merlin, the first theoretical figure, is a textbook example of a creative knowledge worker. He holds a part-time position as a researcher in communication and media science at the local university and he also works as a freelance graphic designer for an advertisement agency. The reason for pursuing these two duties is that Merlin's position at the university was only offered to him as part-time employment. Although Merlin would prefer to work full-time at the university, he also appreciates his current situation of holding two jobs. Merlin has always loved to draw and to paint, and he later on taught himself to work with graphic design software. During his graduate studies he always designed flyers for student parties or covers for music releases from local bands and DJs. At the moment he likes working in the advertisement agency once in a while and without tightly regulated hours. He can earn additional money there by pursuing an activity that he enjoys. Furthermore, he acknowledges that his two jobs nurture each other: what he studies from a theoretical perspective and what he learns from research at the university helps him to improve his graphic designs in the field of advertisement. In addition to this, he learns a lot of practical things while working at the advertisement agency. This gives him an advantage in scientific

56 More information on the ACRE project and its results are available under: http://acre.socsci.uva. nl/index.html (accessed 14 April 2014) 
research, as he is already part of the empirical field. Sometimes, he feels stressed by this life between the worlds of publically financed science and private market advertisement. In science things are regulated in rigid ways, he has to respect the hierarchy and bureaucracy at the university. People live in a 'theoretical bubble', often far from the 'real world'. On the other hand, he sometimes feels dissatisfied with the speed of work in the advertisement agency, where he has no time to reflect on what he is doing. Even though clients expect individualised products and services, his boss has introduced some standard templates for these services in order to raise the productivity. Whereas products are sold as 'tailored to the specific needs' of a client, they are actually what all other clients receive. The continuous switching between these two worlds brings a lot of emotional and mental stress for Merlin. In addition, the pay in both jobs is still below average. Merlin holds a master's degree from a university. Yet, he has the feeling that the time and money he invested in studying does not really pay off at the end of the month. His two jobs lead to bureaucratic problems. His health insurance is related to his employment at the university, but the health insurance company only accepts a limited range of hours being worked in other jobs. Merlin does not have a regular number of hours that he works in the advertisement agency, so he frequently has to go and explain to the health insurance officers that he cannot guarantee he will not exceed that limit and that he cannot predict when and for how long such an excess might occur. Similarly, he pays benefits to the unemployment insurance from the salary he receives at the university. Whenever his temporary contracts as a researcher finish, he has to register for unemployment benefits and explain his professional identity to the labour office, so that they can look for new employment for him. However, the labour officers do not understand that he can do several things: research, communications, and advertisement. In their logic he has to have one professional identity. These things both stress and amuse Merlin, as they show him how much he deviates from standard cognitive models and bureaucratic logics. Given all these difficulties, he always reports being happy in what he is doing. He can pursue his various interests (theoretical and practical ones) in a given professional field (communications). He can keep himself up to date, his intellectual inputs are very welcomed and praised by his colleagues and bosses, and the people around him are friendly, interesting, and stimulate him to begin new projects. Furthermore, in his many years in this city he has constructed a large social network of acquaintances and friends. His sister works in this city, too, and her networks are also available to him. Through these networks, he continuously receives informal and up-to-date information about new developments, projects and actors in the local market. This gives him the opportunity to think up new project ideas and set up new project teams and collaborations. He can also switch between his two institutional affiliations when it comes to organisationally embedding a new project. If neither the university nor the advertisement agency is the right place to pursue an interesting project, he can also do it as a freelancer in other flexibly designed organisations. The informal information flow in the city's networks is important for participating 
in the market and being a recognised player in the field. Merlin would not have the opportunity to get jobs as easily in other cities, where he does not know anyone. In order to remain integrated and recognised, Merlin combines the useful with the pleasant - he attends social events during evenings and weekends where the local creative avant-garde is meeting. During these parties, work life and private amusement are inseparably intertwined. This also has disadvantages, as Merlin remarks. People seem to circulate mentally around themselves in the city. So, once in a while he goes on small trips to other cities to visit friends and relatives. These trips open his cognitive horizon again and distance him from the situation of a local lock-in in his city. He gets inspired by what he sees elsewhere and it helps him to refresh his work back home. Even though Merlin loves his life as it is, he sometimes reflects on how it would be if he had a family. He is in his 30's, still young, and at the moment everything is going well, but his future is still rather insecure. In certain moments he wonders if he would enjoy having a more stable family life with children, something more stuffy and less bohemian than now, but then he concludes: 'Well, let me think about that later, there's still some time'.

\section{Meet Hannah}

Hannah is the textbook example of a person who is deeply rooted in her local environment. Hannah was born in One City, and she grew up in the same neighbourhood where her parents are still living today. She recently moved to another neighbourhood where she and her husband could afford to buy an apartment that is large enough for them and their two small children. She would have preferred to buy one in her childhood neighbourhood and closer to her parents, but prices were too high. Hannah loves her life in One City, and she feels that this place is her home and where she can be herself. For professional reasons she has to travel. It sometimes makes her nervous when her boss sends her on business trips. In other cities she has the impression that people are completely different, and she feels uncomfortable among them. When she arrives in other places, she already longs for the moment when she is back in 'her' city, One City, and close to her family. In such situations, she realises even more how strongly she is related to her city and the people there. She understands their humour and can laugh with them. Furthermore, she has a lot of friends and acquaintances who are very supportive in everyday life. She meets people coincidentally on the streets and chats about the local gossip or the annoying political decisions of the City Council of One City. Having to go on business trips once in a while, Hannah also compares the physical environment and the built infrastructure in her city to that of other cities. She definitely thinks that her city is more beautiful than any other she has visited. As such, when she is elsewhere, she feels homesick. Actually, she only likes to travel if it is for vacation with her family, when she can go with her husband and her children. In these moments it does not matter where they go, only that they go together. Yet, Hannah prefers to stay in the country when travelling with the children, as she does not trust health care abroad, and she is also not 
very fluent in foreign languages. If something happened with the children, she would not feel prepared to deal with foreign institutions (e.g. going to see a medical doctor in a hospital). Her best friend, who she has known since kindergarten, had problems with her small daughter while travelling abroad last year, and she told her it was a 'nightmare'. Therefore, Hannah would rather spend vacation time inside the country. Altogether, Hannah would always identify as being from her city and her country, in which things run 'better' than in other countries. In the future, she definitely wants to stay where she is. She could not imagine living elsewhere. However, Hannah is aware of the changing conditions in which her local lifeworld is embedded. The European Union is affecting her everyday life more and more. She does not really know what to think of that. She would not consider herself competent enough to express a clear opinion, but her gut instincts make her feel opposed to these influences from 'above' and elsewhere. She also observes that the social composition of her neighbourhood is changing. Looking only at her own apartment building, she observes that the nice neighbours - those who had always helped her with carrying the buggy upstairs when her children were still smaller - moved out three months ago. Mr Miller had applied for a better job in another city. Then new neighbours moved into the Millers' apartment. Hannah has met them in the stairway when they moved in, but since they have not spoken much. These people only go to work when Hannah has already brought the children to the kindergarten and has already worked for hours in the office, and these new neighbours come home late from work. Bringing home all their daily shopping so late, Hannah asks herself: 'Where do they shop? The poor cashiers, who have to work so late!' Hannah has observed that the new neighbours have a licence plate from a foreign country, and she is not able to pronounce their family name which is written on the door bell. Hannah wonders about the changes around her, and she is actually very curious about it. She latently feels that the continuity of life in 'her' city is being threatened by those coming in from elsewherethose who redefine everything. This includes the impression that she has to defend the stability of her lifeworld. On the other hand, she knows too little about where this all comes from and where it will lead. For the moment she continues observing and trying to form an opinion.

\section{Meet Daniel}

The third theoretical figure is that of 'Daniel'. Daniel is the textbook example of a multilocal and transnational person. Similar to Hannah, Daniel was born in One City and he started attending school there. Four years before his graduation, his father took a new position in Second City, so the family moved there and Daniel had to leave all his friends and make new ones in Second City. This is not always easy for teenagers, but Daniel managed quite well and learned to adapt his personality to this different context; in turn, he was accepted by the other teenagers in Second City. Actually, after a while, he appreciated the fact that the family had moved and that he was able to compare the two cities. His old friends in One City loved to hear his stories from 
Second City, and his new friends in Second City were interested in stories from One City. Sometimes Daniel also took his friends from one place to show them around in the other place. As Daniel had experienced how it feels to be the 'new' guy from elsewhere, he quickly became friends with Thomas, who came from Second Country with his parents. While Daniel's classmates in Second City were interested in One City, they were not interested in Second Country stories from Thomas. Only Daniel was; and Thomas' stories about Second Country made Daniel even more curious to go there. Consequently, he went to Third City in Second Country for an exchange year, where he learnt how it feels to be a foreigner, to express oneself in a foreign language and to live in a more or less different culture. Daniel learnt to compare perspectives and opinions, and he learnt that his own national background does not represent the only lens for looking at the world. After graduation, he was even more curious to learn more about foreign countries. He started studying in Fourth City in Third Country, and he was very happy that his parents supported this decision. This allowed him to follow his personal interest in discovering the new and unknown, while being able to break out from the known. In Fourth City he met Anna, who comes from Fifth City in Fourth Country. They became a couple and still live in Third Country. Daniel has taken a job in the local branch of a globally operating company. The company frequently sends him around Europe to provide services to different clients. When Daniel's boss realised his cultural skills and foreign language proficiency, he offered Daniel to prepare market entry and set up the first branch of the company in One Country. Daniel liked the idea of reinforcing links to his country of origin. Whereas his home has become Fourth City, where he shares an apartment with Anna, and where they found an international circle of friends, and where he appreciates the cosmopolitan atmosphere, he still feels rooted in One Country, too. Upon accepting the job, he had to spend much time in One Country, and his boss decided to locate the first branch to Sixth City, where Daniel rented a furnished apartment which could be used quickly. But this apartment could also be left again without much effort, if the business would fail. From that time on, Daniel circulated between One Country and Third Country, between Sixth City and Fourth City, between his work life and his private life. Additionally, he used some weekends in One Country to go and see his parents in Second City, or old friends in One City. On other weekends he met up with Anna in Fifth City in Fourth Country to see her parents. This multilocal arrangement allowed Daniel to combine the amenities of different places and countries within his own lifeworld. Anna also started travelling to One Country more often and her life became more mobile. Hence, Anna and Daniel developed new techniques to keep in touch while physically being separated; they used Skype calls to update each other about their daily news. Sometimes they sent each other small gifts when they found something that reminded them of each other. They also became routinised travellers, and developed routines for dealing with airports and train stations, and they became more relaxed in problem situations with spontaneous delays and changes in travel plans. They somehow felt at home in all their places and also in their travel between 
these places. This has also translated into identitary problems. When Daniel meets other people and has to introduce himself, he sometimes has problems fulfilling the expectations of others. Others most often expect a person to be from one place in one country. But Daniel feels as if he is from several places in several countries, which are all part of his personality and his lifeworld, and which in combination make up his identity. He accepts with humour how others expect him to answer, and according to the situation he identifies with one out of several different identities. Sometimes he mirrors their expectations; in other situations he rather prefers to confuse them. Indeed there are more serious problems in such a lifestyle. Being located in different places means that he is often present in the one place, while he wants or needs to do things in the other place. Sometimes he wants to embrace Anna in Fourth City after she had trouble with her boss, but he is in Sixth City. Sometimes he is in Fourth City, but he needs a certain book that he forgot in Sixth City. In other moments, he finds himself in the mood to go and have a beer with his best friend in Second City, while being annoyed by Anna's father in Fifth City, who is trying to convince him to take a more monolocal job again in Fourth City in order to have a 'real' everyday life with Anna, and which could be a basis for founding a family. In all these moments when he briefly feels dislocated in the immediate situation, he remembers all the advantages of such a lifestyle. He has learned about so many perspectives and contexts that he has become very relaxed about the decreasing stability of lifeworlds which monolocals often bemoan. He knows that one can individually shape one's own life in a variety of directions; there is not just one way that things should or could be done. Sometimes, when Daniel goes to see old friends in One City, he also encounters Hannah on the streets. They know each other from his early school years. Today, both Daniel and Hannah feel relatively uncomfortable in these situations when they meet coincidentally. Being polite people, they stop to say hello and chat a while. However, while chatting they have very few things to share. Whereas Hannah is only wellinformed about things in One City, Daniel could only chat about things concerned with living in between Third Country and One Country, or comparing life in different cities. There is something of a mental barrier between their lifeworlds and the topics they could speak about. So, they both decide to keep it short and go on with their lives - 'Have a good time, bye!' they say. And Daniel then also thinks about how his life would be, if he lived like Hannah, and he concludes: 'No, that wouldn't suit me! My life could probably be a bit more focused in geographic terms, but not only in one place.'

These three theoretical figures of Merlin, Hannah and Daniel describe the sometimesconflicting contexts in which people today construct their own lifeworlds. In particular, increasing mobility, to which people adapt in very individual ways, leads to a great variety of lifestyles, or as Braidotti (2011: 3) says: 'At the start of the third millennium, a diffuse sort of nomadism has become a relevant condition for a great deal of the world's denizens.' The increasing individuality of lifeworlds also causes tensions with 
organisational structures and institutions in which individual actors are embedded and by which they are influenced - their lives simply do not fit bureaucratic and scientific expectations anymore. Weichhart (2010: 66 ${ }^{57}$ ) states: 'In the second modernity it has become even more difficult than before to describe and understand the world, that we call the 'reality'.' With reference to Beck et al. (2004), Weichhart (2010) mentions that scientific description today - studying phenomena in the second modernity increasingly has to 'differentiate in inclusive terms', while it 'differentiated in exclusive ways' during the first modernity.

I understand Weichhart's idea as an invitation to look for the junctures of supposedly exclusive phenomena. In relation to the theoretical figures of Merlin, Hannah and Daniel, the task is now to imagine a possible 'inclusive differentiation' of their lifeworlds, a combination of all the three theoretical figures within one character. Here, I came across several paradoxical elements that pose problems to such a task and thus reveal interesting research questions.

\subsection{The Multilocality Paradox}

The three strands of literature - as illustrated in the three theoretical figures - express different understandings concerning the individual's place relatedness and belonging. Creative knowledge workers, such as Merlin, identify mainly through their professional identity. This is composed of different professional roles which all feed into this identity. However, they are relying on local networks and as such they are also identifying with one specific place in which they are strongly embedded in professional terms. These places often provide economic resources. A place can be known elsewhere for a very specific segment of creative knowledge work. For example, Hollywood (and more recently Bollywood) have become centres of the global film industry, Berlin is known for its electronic club music, and Milan and Paris are known for their fashion design. Therefore, being based in and identifying with a very specific locale might make sense for creative knowledge workers. They can use place affiliation as a symbolic input for self-branding, for expressing their market value. However, these place identities are not stable in time. Places can lose their reputation in the market. For example, the book industry, which was famous in Leipzig, lost its importance after World War II, and Frankfurt developed as the main location of publishing houses and all institutions in this sector. Depending on their specialisation, it can make sense for creative knowledge workers to stress their place attachment and belonging at a given moment, and to make it part of their personal identity. On the other hand, creative knowledge workers are also suspected to shape their environments more actively

57 Translated by the author from the German text: 'Es ist in der Zweiten Moderne noch schwieriger geworden als früher, die Welt, das, was wir die ,Wirklichkeit' nennen, zu beschreiben und zu verstehen.' 
than other groups. They sustain the development of 'creative cities', with all its consequences (gentrification, displacement and segregation, brownfield redevelopment, etc.). The rooted people, such as Hannah, mainly identify with one individual place and with its respective upper scales such as a region or a country. Furthermore, this type of place-based identity is stable in time, and it is relatively easy to treat it in empirical study, as things seem clearer. Hannah is an ideal type in terms of place-based identity and rootedness. It becomes more difficult, if one looks at the more mobile case of the multilocal transnational people such as Daniel. Obviously, they are not only related to one place, but to several places.

Here, the paradox consists of the fact that place-based identity and rootedness is theoretically described as something which is based on personal experience and spending time in one place. We have learnt that in identification processes symbolic content - be it related to places, objects, or persons - is important as a reference for achieving a coherent self-conception about 'who I am', 'who is like me', 'who is not like us', and 'how we are different from each other'. If it comes to place-based identification, references might be the place itself, with its certain ascribed characteristic and symbolic value (the narrow sense of placed-based identification). In a wider sense, place-based identification could also relate to a group of people who inhabit a certain territory (direct interaction or only an imagined community). This is already a complex process when it comes to dealing with one place. Now, transnationalism and multilocality research teach us that people live their everyday lives in different nations and different cities simultaneously. Here it becomes difficult: multilocality and transnationalism research provide first insights into how we could understand place-based identity as part of multilocal arrangements, but literature on creative industries does actually not speak about multilocal arrangements. Knowing that places and place attachment are important resources in creative knowledge work, it sounds rather contradictory to be mobile and to be a creative knowledge worker.

As a consequence of this paradoxical situation, I think the following intriguing questions have to be studied when it comes to mobile creative knowledge work:

- On a very descriptive level, which places actually constitute the action spaces of multilocal creative knowledge workers?

- How does place-based identification work in the context of multilocal creative knowledge work?

- How much of identification of creative knowledge multilocals is actually based on place?

- Are there any other categories of identification that emerge among creative knowledge multilocals (social groups, profession, or mobility instead of rootedness)?

- What impacts do their multilocalities have on their potential to actively shape their cities?

- What relation exists between different places in the perception of multilocal creative knowledge workers? 
- Are places equally important, or can we observe an unequal distribution of meaning and importance between places within one multilocal lifeworld?

- Are creative knowledge multilocals still 'citizens' of a particular place, who engage in local civic engagement, neighbourhood initiatives and governance activities?

The literature allows some theoretical expectations here: if people travel a lot and their everyday lives are distributed to different places in different nations, then getting involved locally as well as nationally might become more difficult. The interplay of absence and presence leads to a continuous interruption of identification processes which themselves could be imagined as a fractioned development path. The face-toface interaction with people in the involved locales/nations is continuously interrupted, and it could be difficult to deepen or stabilise relationships. Upon arrival in a new place, the inner logic of social life in one place could not be learnt as profoundly as in a monolocal situation with extended experience and detailed insights. Thus, the social element of place-based identity is less accessible. When arriving in new places, multilocal creative knowledge workers do not know the people in these places. The multilocals do not know how the locals are, and if they actually want to identify with these locals. Consequently, it could be suggested that place-based forms of identification are difficult to establish in multilocal settings. Creative knowledge multilocals might opt for other reference categories - such as professional peers, loved ones or family members - which are comprehensible and less complex even while being geographically absent or distant.

Furthermore, it might also be that the combination of different localities/places in multilocal creative knowledge workers' lives leads to a development of more hybrid relations to places. In particular, creative knowledge workers might make use of different and hybrid place attachment in terms of career building, or input and stimulus for their work. Florida, for example, suggests that - in line with non-conformity, which is a valued orientation among this group - creative knowledge workers might exhibit a 'mixing of multiple creative identities' (2002: 78).

Finally, this multiplicity of identity might also translate into difficulties in feeling a sense of belonging to one place. Petzold (2010) emphasised the phenomenon that some multilocals actually like being multilocal, and they indeed developed a multiple attachment to various places. Petzold terms this observation translocality. In contrast, he also found a group of people who have to integrate several places into their everyday life, but who perceive their multilocality as enforcement by external constraints (e.g. labour market conditions). Consequently, the latter do not equally feel as if they belong to 'all' their places. They rather have one central place in their lifeworld. Petzold calls this phenomenon 'interlocality'. He then puts the translocality versus interlocality continuum on the horizontal axis of his 'crosshairs' of multilocality research (Petzold, 2010: 251). In addition, Weiske et al. (2009) studied multilocal households and the ways they give sense to a multilocal life. They also found a type of households that they call 'dispatched' (Verschickung). This type perceives multilo- 
cality as a displacement of individual household members. The household members, who are actually travelling, do not develop wider relations to all their places; rather, they are very selective. They remain cognitively monolocal, while physically travelling. As such, they feel dispatched.

Given these scientific results, I would assume that if a person does not feel that they belong to a place, the respective feeling of solidarity/empathy for other people at this certain place might be low. I suggest that creative knowledge multilocals might also develop such selective forms of belonging and use places for their individual purposes rather than completely living in them as 'caring' and responsible citizens. This means that their opportunity for civic engagement is rather small, and their involvement in local issues and local development is less probable.

\subsection{The Mobility Paradox}

Hannah - like other rooted monolocals - lives in a stable lifeworld which is affected by the increasing mobility only in mediate ways. Other people who are more mobile and arrive at her place are causing changes in the nature of her place. Yet, Hannah only moves around if necessary for her job, and rarely for private holidays. In both her private and professional life, travelling is a subordinated element. Merlin - the creative knowledge worker - is described as a person who is embedded in a place, but who needs to escape from it once in a while to find inspiration elsewhere. To Merlin, travel has a more positive connotation than for Hannah. Additionally, his travel often includes private and professional interests in one and the same trip. For Merlin, travelling and mobility is not a central element in his lifeworld. He is rather travelling in mental terms when it comes to creation and thinking up new things. Finally, Daniel the transnational multilocal - is someone whose life is heavily influenced by physical mobility. It is a very central element, and he is somehow rooted in mobility.

The paradoxical constellation is that mobility is still considered an antagonism to belonging and rootedness. Traditional perspectives would argue for exclusiveness, as Petzold (2010: $240 \mathrm{f}^{58}$ ) points out when arguing for the novelty of the multilocality perspective: 'Dwelling and mobility are generally thought of as contradictory phenomena and they are related to disparate activities: dwelling, understood as sedentariness, is considered a pre-condition for the development of enduring social relations, shared cultural knowledge and last but not least the formation of local identification. By

58 Translated by the author from the German text: 'Wohnen und Mobilität stehen jedoch gemeinhin in einem Widerspruch zueinander und werden mit disparaten Handlungen verbunden: Wohnen als Seßhaftigkeit gilt als Voraussetzung für die Entwicklung stabiler sozialer Beziehungen, kulturell geteilten Wissens und nicht zuletzt für die Ausbildung einer lokalen Identifikation. Mobilität meint demgegenüber Bewegung, Fluss und Entbettung aus den genannten sozialen, ökonomischen und kulturellen lokalen Strukturen.' 
contrast, mobility means movement, flux and disembedding from the mentioned social, economic and cultural local structures.' Here, dwelling is one constituting element of being rooted in a place, which only serves as an example. Other constituting elements such as place-based identity, the feeling of belonging in terms of Heimat/home and psycho-social sedentariness might be thought of in similar ways as opposed to continuous mobility. If we now look at the creative knowledge worker, who is actually making use of their local embeddedness for professional ends, the mobility-induced disembeddedness could even be a professional disadvantage. So, the main questions in this respect are:

- What does mobility mean in the lives of mobile creative knowledge workers?

- Is mobility eroding the stability of lifeworlds and professional situations of mobile creative knowledge workers?

- How do mobility and belonging interrelate in terms of personal meaning and professional symbolic value in the context of creative knowledge work?

- Can mobility become a constituting element of identity and belonging for creative knowledge workers?

- Can mobility even become a professional advantage?

- How can the absence/presence duality be understood?

- How do mobile creative knowledge workers appropriate and adapt to new places?

- How do they integrate new places into their lifeworld?

- Have they developed routines in spatial orientation and appropriation?

Again, we could formulate some assumptions that result from the literature. First, we can think of mobility as being both beneficial and unfavourable to workers in creative industries. On the one hand, it might be that living in between two places can multiply the resources that are available to individual creative knowledge workers. Access to several local networks might be valuable in terms of having more options to participate in interesting projects, having more stimuli for creation and innovation, as well as having better access to clients and customers. On the other hand, the duality of absence and presence comes along with mobility. In particular, the aspect of absence might be harmful to the integration of a multilocal creative knowledge worker into their various local networks. Local and more immobile people might feel irritated or even disenchanted by such a circular behaviour of mobile creative knowledge workers. As a consequence, the multilocal creative knowledge workers might be refused complete membership in local networks during moments of presence. Here, Dirksmeier (2012) provides the first valuable insights. He has studied how a Bavarian village was affected by a high share of multilocal second homeowners from larger cities. These multilocals bought property in the village, and they mainly use that property during weekend trips or vacation. As such, most of the time these houses and apartments are not inhabited by their multilocal owners. Their temporary absence becomes visible in the public life of the village (e.g. through closed window shutters, untended gardens). This phenomenon results in a negative village atmosphere, 
and the native immobile inhabitants feel disturbed by their multilocal compatriots. Dirksmeier therefore wants to include the impact of the absence/presence duality on places, particularly their physical and social environments, into the study of multilocality. He says (2012: 68f.59): 'The interdisciplinary research on multilocality is currently concentrating on the multilocal individuals and disregarding the perspectives of the respective continuously present inhabitants of the frequented spaces. Research results that declare multilocality as a genuinely positive aspect only can be achieved in this manner. [...] Particularly human geography would pose and answer further interesting, and in future more relevant questions for research, if it applied a theory of multilocality which keeps in mind phenomena of absence and its impacts.' Thus, we can see that mobile people seem to have an influence on the atmosphere and vitality of local communities in the places that form part of their everyday lives. Finally, we should probably question a perspective which understands a society as consisting of a group of 'mobile' people, on the one hand, and a group of 'immobile' people, on the other hand. With his concept of Polytopizität, Stock (2009) presented a perspective in which embeddedness (Verankerung) and disembeddedness (Entankerung) have to be thought of as parallel components of mobile lifeworlds. Similarly, Bonß et al. (2004) suggest that there is no opposition between the 'mobiles' and the 'immobiles'. In the second modernity, a more differentiated pattern has emerged in which new mixed types occur, e.g. the 'mobile immobiles' or the 'immobile mobiles'. Also Petzold acknowledges that such new combinations of mobility and sedentariness could be observed as empirical phenomena. With his 'crosshairs' of multilocality (Petzold, 2010: 251), he presents a theoretical and terminological framework in which the possible theoretical perspectives could be found on the vertical axis - a continuum - between the extreme poles of 'focussing on sedentariness' and 'focussing on mobility'. According to him, individual lifeworlds will always consist of both mobility and immobility, but it depends on the researcher's perspective how this combination is looked at.

\subsection{The Transnationalism Paradox}

Hannah is a person who is deeply rooted in her city. Thus, her main reference frame for everyday life is the local. Yet, during her rare trips abroad she becomes aware of her nationality and what this means in terms of her everyday life. She knows that

59 Translated by the author from the German text: 'Die bisherige interdisziplinäre Multilokalitätsforschung konzentriert sich momentan auf die multilokalen Individuen und vernachlässigt den Blickwinkel der jeweils dauerhaft anwesenden Bewohner der frequentierten Räume. Nur so können Forschungsergebnisse erzielt werden, die Multilokalität als genuines Positivum deklarieren. [...] Gerade die Humangeographie würde mit einer solchen resultierenden Theorie der Multilokalität, die Abwesenheitsphänomene und deren Auswirkungen mitdenkt, weitere interessante und in Zukunft akut werdende Forschungsfragen aufwerfen und beantworten.' 
the national frame embraces her local place. The national influences her local life, but Hannah does not always consciously perceive herself in the national context. For Merlin, the picture is a bit different. As a creative knowledge worker, Merlin is also rooted in the local, but his professional field brings along a strong consciousness regarding the national scale. In particular, the cultural aspect of the nation and, to a lesser extent, the region is also important to him. Working as a creative knowledge worker, culture is one of the main resources on which he draws. He needs to be proficient in the language, he must understand puns and equivocations, and he has to have a sense of humour to be able to joke. In sum, he needs to understand the symbolic and semantic system of the culture in which he operates. Thus, he deals with the spatially located culture in his place. In contrast, Daniel compares different cultural environments to each other. By doing so, we can suspect Daniel of creating his own 'transculture' which is not placed in a specific locality, but which is rather bound to his person and his social networks which transcend geographic barriers.

The paradoxical situation here is that a creative knowledge worker who relies on their competence in playing with a locally or nationally embedded culture cognitively does not fit with transnational mobility. One can imagine that multilocality, which actually occurs within one nation and one national culture, might cause fewer problems. Yet, I think it is rather unclear how creative knowledge workers cope with different cultures in transnational settings. This again reveals some interesting questions:

- How are the national and local scales actually interrelated in creative knowledge workers' transnationality?

- Do reference frames become multiscalar?

- Do creative knowledge workers also relate to supranational scales (e.g. Europe, the European Union)?

- Do transnational creative knowledge workers develop transcultural products and services, or do they instead stick to the international exchange of national ones?

Again I would present some preliminary theoretical assumptions. Given that people's reference frames consist of different scales ever since nation-states superseded the city-states, it is nothing new that place-based identification and belonging is somehow multiscalar. However, due to European integration and globalisation, new scales have emerged (e.g. EU) or have become less abstract and can better be experienced (through all forms of available physical, imaginative and virtual travel). The importances of single scales for societal organisation have also changed ('the revival of the region as scale'). If subnational and supranational scales are added to the catalogue of possible scales for place-based identification, one could suggest that creative knowledge transnationals might integrate them more easily into their reference frames because their frequent travelling allows them to experience e.g. the supranational scale more directly in their everyday life. Andreotti et al. (2010) assume the hypothesis that transnationally mobile people withdraw to a certain degree from local engagement as they at least partially 'exit' the local scale - in the Hirschman 
sense - to profit from a transnational scale. Andreotti et al. (2010) studied managers in the larger European cities of Milan, Paris, Madrid and Lyon, and they found that there are different types of transnationally mobile managers. First, there are managers whose physical mobility is rather low, and who base their transnationalism largely on virtual practices. These managers often stick to local and national contexts. These rooted managers - even though working in transnational environments - strictly relate to the local community, having large circles of friends and family members in their neighbourhood or city. Furthermore, they use local public infrastructures and services. Andreotti et al. (2010) conclude that this finding contradicts the hypothesis of the de-territorialised mobile and cosmopolitan elite that is the opposite of the normal local people (Andreotti et al., 2010: 13ff.). On the other hand, there are managers whose physical mobility is high and who also engage in virtual transnationalism. These managers indeed develop partial exit strategies from the local and national contexts. The exit strategies concern the interaction with local neighbours and participation in local associations and initiatives. Even though they might profit from local offers, they do not actively engage for the benefit of the local community (Andreotti et al., 2010: 15f.).

Furthermore, we could also argue that the national scale will lose its dominant power for identification once other categories emerge. In particular, the immediate local level of the neighbourhood is of symbolic importance for creative knowledge multilocals (often illustrated as a city centre location with old-industrial urban fabric). Thus, I suggest that the local level is very important to them, whereas the national might exist in a subordinated position, if the local is directly combined with the supranational scale through transnational life experience. A characteristic of creative knowledge workers is their emphasis on tolerance and open-mindedness - close to a Kantian cosmopolite. We could thus also suggest that the global scale might be an important scale for creative knowledge transnationals, too.

\subsection{The Character of 'Place' in Mobile Creative Knowledge Lifeworlds}

So far, I have unreflexively used the term 'place', and this has a reason. Looking at the above-mentioned phenomena from a geographer's perspective, it would be intriguing to look at 'place' by using existing theoretical perspectives. However, I would like to keep my perspective unlimited from such theoretical considerations. Following the logics of grounded theory (cf. section 6.3.1), I will look at my study group's own - and thus an empirical - understanding of 'place'. Place, which I thus far conceive of as a term to vaguely circumscribe the local scale, seems of central relevance in the literature on creative industries (cf. chapter 2), 'roots' (cf. chapter 3) as well as 'routes' (cf. chapter 4). Without defining it precisely, all these strands of literature mention it as an important category of the individual lifeworld of people. Therefore, I would like to 
leave it open for my interview partners to define how 'place' can actually be characterised in the context of transnationalism and multilocality. In the end, answering this question is also one main aim of this book.

As a final remark, I would like to stress that this research project is an exploratory one, and I understand these sets of questions around 'creative knowledge multilocality' (cf. section 5.1), 'creative knowledge mobility' (cf. section 5.2), 'creative knowledge transnationalism' (cf. section 5.3) and 'places in creative knowledge lifeworlds' as fields of interest that guided the empirical fieldwork and the analysis. However, these fields of interest should not be understood as a rigid catalogue of research questions that should all be answered in the frame of this book. They do not reflect a straightforward operationalisation process as is used in quantitative research designs. My aim is to answer as many of these questions as possible, but I do not expect to find an answer to everything that interests me as outlined above. 